\title{
Artigo
}

\section{Sou mãe: e agora? Vivências do puerpério}

\author{
Paula Azevedo Campos* \\ Terezinha Féres-Carneiro \\ Pontifícia Universidade Católica do Rio de Janeiro, Departamento de Psicologia, Rio de Janeiro, RJ, Brasil
}

\begin{abstract}
Resumo: $O$ presente estudo é parte de uma pesquisa mais ampla sobre maternidade e cuidados na primeira infância, e tem como objetivo investigar como as mulheres vivenciam o puerpério atualmente. Para tanto, foi realizada uma pesquisa qualitativa, na qual foram entrevistadas dez mulheres das camadas médias da população carioca, atuantes profissionalmente, com idades entre 29 e 37 anos, casadas, legalmente ou não, heterossexuais primíparas e com o filho(a) entre 8 meses e 2 anos de idade. Os resultados foram analisados segundo o método de análise de conteúdo na sua vertente categorial. Para atingir os objetivos deste estudo, serão discutidas as seguintes categorias de análise: baby blues; rede de apoio; e a história não foi bem assim... Os resultados apontaram o puerpério como um período idealizado pelas mulheres, mas vivido com sofrimento e instabilidade emocional. Constatamos a importância da rede de apoio para a mãe e o bebê.
\end{abstract}

Palavras-chave: maternidade, puerpério, baby blues, rede de apoio.

\section{Introdução}

A gravidez é considerada um período crítico de transição, biologicamente determinado, capaz de produzir um estado temporário de instabilidade emocional em virtude das mudanças no papel social e na identidade, além das adaptações interpessoais e intrapsíquicas que a mulher precisa fazer. Tal período se estende ao puerpério, que também comporta modificações fisiológicas, assim como mudanças na rotina e no relacionamento familiar (Maldonado, 2013). No pós-parto ocorre uma mudança de foco para o bebê, no entanto, a mãe ainda precisa de cuidado e amparo, devido à ansiedade que esse momento desperta na mulher. Costa (2018) aponta em seus resultados o sofrimento como sendo intrínseco ao puerpério e as mudanças corporais como importante fator dentre os que contribuem para esse estado das mães.

Nessa direção, a melancolia maternal parece estar associada a uma combinação de perdas e adaptações que a puérpera vivencia, como as mudanças no corpo, a experiência com o bebê real e não mais idealizado, e as próprias necessidades que não podem ser atendidas em razão das demandas do bebê (Sarmento \& Letúbal, 2003). A depressão pós-parto pode ser conceituada como um espectro que engloba três categorias: melancolia maternal, conhecida na literatura americana como baby blues; depressão pós-parto (DPP); e psicose puerperal. O baby blues ocorre nos primeiros dias após o parto, dura em média entre uma e duas semanas, e acomete de $50 \%$ a $80 \%$ das mães (Bass \& Bauer, 2018; Kible \& Wells, 2019). Estudo realizado na Índia revelou que,

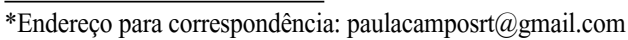

das 64 mães puérperas participantes da pesquisa, 94\% tiveram baby blues e somente 6\% tiveram DPP (Jayasankari, Kirthika, Priya, \& Varghese, 2018). Os sintomas podem incluir ansiedade, choro, apetite diminuído, exaustão, perda de interesse nas atividades habituais, mudanças de humor, tristeza, problemas no sono e preocupação. No entanto, mesmo tendo que lidar com esses sintomas, a mães que apresentam o quadro de baby blues não têm rejeição ao bebê, e o tratamento pode ser feito com apoio emocional (Bass \& Bauer, 2018).

Já os sintomas da DPP são mais graves, persistem por mais de duas semanas e, normalmente, requerem intervenção médica. Eles incluem a perturbação do apetite, diminuição de energia, sentimento de desvalia ou culpa excessiva, sentimento de inadequação, rejeição ao bebê e ideação suicida (Sarmento \& Letúbal, 2003). Em sua grande maioria, os sintomas da DPP são desenvolvidos nas quatro primeiras semanas após o parto, mas é possível ocorrerem nos 12 meses subsequentes ao parto (Davidson, 2016). A DPP acomete cerca de $15 \%$ das puérperas e a psicose puerperal cerca de $0,2 \%$ das mulheres (Degner, 2017).

A metanálise conduzida por Silva (2013) revelou uma prevalência maior de DPP em países em desenvolvimento. Esses dados vão ao encontro de estudos que evidenciam uma elevada relação da DPP com condições sociodemográficas desfavoráveis (Lima, Ravelli, Messias, \& Skupien, 2016; Melo, 2011). Nessa direção, uma revisão sistemática sobre a magnitude da depressão pós-parto no Brasil identificou uma prevalência de cerca de $20 \%$ de DPP em unidades hospitalares terciárias, e 30 a 40\% em unidades básicas de saúde (Lobato, Moraes \& Reichenheim, 2011). Esses estudos apontam os agravos à saúde mental materna na esfera da saúde pública. 
Em relação ao baby blues, devido à frequência mais alta dos casos, essa condição é considerada um estado fisiológico possivelmente associado a mudanças biológicas, sendo sua intensidade influenciada por fatores psicológicos. A baixa autoestima materna e altos níveis de estresse em relação aos cuidados com o bebê foram identificados como fatores significativos na intensidade do baby blues. Esse quadro parece ocorrer devido a uma crescente reação emocional a sentimentos agudos, que leva a uma labilidade afetiva e não a um estado de tristeza (M'baïlara et al., 2005), sendo descrito por algumas mulheres como uma "montanha-russa emocional" (Jayasankari et al., 2018).

Nenhuma intervenção isolada é apontada como capaz de controlar o desenvolvimento do baby blues, no entanto a rede de apoio é considerada um dos fatores de maior importância para a sua prevenção (Cardoso \& Vivian, 2018; Cunha, Ricken, Lima, Gil \& Cyrino, 2012; Davidson, 2016; Maliszewska, Świątkowska-Freund, Bidzan, \& Preis, 2016). Nesse sentido, podemos afirmar que a presença de uma rede de apoio funciona como um dos fatores de proteção à maternidade. Não somente o apoio instrumental, mas afetivo, fornecendo encorajamento para a que a mulher se sinta autorizada em sua função materna (Theme Filha, Ayers, Gama \& Carmo Leal, 2016). Outros aspectos citados na literatura podem prevenir o baby blues: acompanhamento psicológico (Manente \& Rodrigues, 2016; Cunha et al., 2012); padrões regulares de sono (Davidson, 2016; Maliszewska et al., 2016); e atividade física, durante a gravidez e no período pós-parto (Kołomańska-Bogucka \& Mazur-Bialy, 2019).

De acordo com Stern (1997), há inegável existência de aspectos psicobiológicos e, principalmente, hormonais, que predispõem de alguma forma a mãe a exercer a maternagem. No entanto a amplitude desse fenômeno, denominado por ele de constelação da maternidade, só pode ser contemplada à luz do contexto histórico e cultural em que a mãe está inserida. Desse modo, o autor descreve a constelação da maternidade, e seus temas relacionados, como um fenômeno observado no Ocidente, em sociedades pós-industriais, e não algo inato ou atemporal, sendo o aspecto sociocultural preponderante no desenrolar dessas influências psicobiológicas. $\mathrm{O}$ autor chama de constelação da maternidade a singular organização psíquica da mulher que se inaugura com a chegada do bebê, particularmente com o nascimento do primeiro filho. Essa nova organização psíquica é variável, podendo durar meses ou anos. Mas, mesmo sendo temporária, é considerada um construto psíquico independente, composto por novos desejos, medos, fantasias, sensibilidades e ações.

Dentre os fatores culturais de influência na constelação da maternidade Stern (1997) destaca: a valorização do bebê, seu desenvolvimento e bem-estar; a valorização do papel da mãe e a importância dada à sua responsabilidade em relação aos cuidados do bebê, mesmo que parte desse cuidado seja transferido a um terceiro; a expectativa de que o bebê seja desejado e que a mãe o ame; a expectativa de que haja um ambiente de apoio para que a mãe possa se dedicar ao bebê; e, por fim, a falta de um provimento social eficaz, capaz de preparar e dar apoio para que a mãe exerça o papel maternal.

Stern (1997) aponta quatro temas principais relacionados à constelação da maternidade. O primeiro é o tema vida-crescimento, em que a mãe se vê diante da situação inédita de manter o seu bebê vivo, proporcionando um crescimento saudável. Isso a fará questionar se é naturalmente dotada para isso, se como animal humano, após conquistar a sobrevivência individual e conseguir reproduzir, será capaz de fazer viver o seu bebê.

O segundo tema, o relacionar-se primário, refere-se ao envolvimento emocional da mãe com o bebê, no seu primeiro ano de vida, e engloba a constituição de laços de apego, proteção e regulação do bebê. Está relacionado fortemente à cultura, que nem sempre é consonante com as disposições da mãe, o que pode torná-la temerosa de sua capacidade de amar, de ser espontânea com o bebê, de relacionar-se com ele a ponto de identificar suas necessidades. Desse modo, pode-se questionar: será ela vazia, egoísta ou até mesmo deficiente?

Na linha dessas ideias, Badinter (1985) considera a maternidade particular à vivência de cada mulher e aos valores correspondentes ao momento histórico em que vive, e não inerente à sua natureza. Desse modo, afirma que as formas de maternagem são múltiplas e não podem ser contempladas de modo radical, no entanto ressalta que a grande maioria das mulheres se move entre opiniões que têm como base a noção do amor materno como inato, sem, contudo, se sentirem representadas por essa visão. De acordo com Azevedo e Arrais (2006), embora a experiência materna comporte oscilações, transformações e imperfeições, a visão romanceada de que a mãe não demonstra fragilidades, que possui uma vocação inata ao sacrifício, associada à incapacidade da mulher de corresponder a esse ideal, contribui para perturbações na vivência da maternidade, como é o caso da depressão pós-parto.

Com isso, podemos salientar a relevância do terceiro tema da constelação da maternidade que diz respeito à matriz de apoio, tão necessária, em vista da enorme demanda que não somente o filho, mas também a sociedade confere à mãe. Essa função foi, tradicionalmente, delegada ao universo feminino, nas figuras das parteiras, enfermeiras, avós, tias, irmãs e doulas. Os homens não eram incluídos na dinâmica de cuidados do bebê e da mãe e só mais recentemente passaram a ocupar um papel importante nessa função. Assim sendo, para que a mãe possa desempenhar as tarefas de manter vivo o bebê e de propiciar seu desenvolvimento psíquico-afetivo, a matriz de apoio tem dupla função: atender suas necessidades vitais, afastando-a temporariamente das obrigações do mundo externo; e prover apoio psicológico, dando acolhimento, valorizando-a, fazendo com que a ela se sinta apreciada e instruída (Stern, 1997). 
O quarto e último tema, denominado "reorganização da identidade", diz respeito à transformação na identidade de filha para mãe, ao se tornar genitora e introduzir uma nova geração. Essa reorganização da identidade conduz a uma nova distribuição de tempo e investimentos emocionais. Não é de se admirar que a nova mãe reative modelos positivos e negativos de maternagem, dado o contexto evocativo presente de intensa interação mãe/bebê, que irá convocar os esquemas de interação vivenciados com sua própria mãe. Nesse sentido, o nascimento do bebê mostra ser um período crítico também no desenvolvimento da mãe. Segundo Bowlby (1997), é provável que seja universal a ativação do comportamento de apego da mãe de um bebê pequeno, fazendo com que também as mães necessitem ser cuidadas e confortadas nesse momento. Nessa direção, a literatura vem apontando a importância de uma rede de apoio para as mães, o que sugere aumentar a sua responsividade à criança e trazer benefícios à família a curto e longo prazo (Goldstein, Diener, \& Mangelsdorf,1996; Rapoport \& Piccinini, 2006).
Com base em tais considerações, o presente estudo, que é parte de uma pesquisa mais ampla sobre maternidade e cuidados na primeira infância, tem o objetivo de investigar como as mulheres das camadas médias da população carioca vivenciam o puerpério atualmente.

\section{Método}

Foi realizada uma pesquisa de campo exploratória, utilizando uma metodologia qualitativa.

\section{Participantes}

Participaram da pesquisa dez mulheres das camadas médias da população, atuantes profissionalmente, com idades entre 29 e 37 anos, casadas, legalmente ou não, heterossexuais primíparas, com o filho entre 8 meses e 2 anos de idade, e residentes na cidade do Rio de Janeiro.

Tabela 1. Dados das participantes, filhos(as) e seus cônjuges

\begin{tabular}{ccccccc}
\hline & Idade & Profissão & Sexo do bebê & Idade do bebê & Idade do marido & Profissão do marido \\
\hline Mãe 1 & 29 & Arquiteta & $\mathrm{M}$ & la e $4 \mathrm{~m}$ & 34 & Designer \\
Mãe 2 & 37 & Jornalista & $\mathrm{F}$ & la e $10 \mathrm{~m}$ & 38 & Jornalista \\
Mãe 3 & 33 & Servidora pública & $\mathrm{M}$ & $1 \mathrm{a} \mathrm{e} 7 \mathrm{~m}$ & 33 & Empresário \\
Mãe 4 & 36 & Produtora de teatro & $\mathrm{F}$ & $1 \mathrm{a} \mathrm{elm}$ & 42 & Autônomo \\
Mãe 5 & 34 & Atriz & $\mathrm{F}$ & 2 anos & 34 & Músico \\
Mãe 6 & 30 & Pedagoga & $\mathrm{F}$ & 2 anos & 32 & Empresário \\
Mãe 7 & 37 & Gerente de TI & $\mathrm{F}$ & $1 \mathrm{a} \mathrm{e} 5 \mathrm{~m}$ & 47 & Diretor de TI \\
Mãe 8 & 37 & Servidora pública & $\mathrm{F}$ & $1 \mathrm{a} \mathrm{e7m}$ & 37 & Analista de sistemas \\
Mãe 9 & 35 & Médica & $\mathrm{F}$ & $10 \mathrm{~m}$ & 36 & Cirurgião \\
Mãe10 & 36 & Publicitária & $\mathrm{F}$ & $8 \mathrm{~m}$ & 34 & Gestor de projetos \\
\hline
\end{tabular}

Notas: Idades em anos; a: anos; m: meses; M: masculino; F: feminino; TI: tecnologia da informação.

\section{Instrumentos e procedimentos}

Para a obtenção dos dados, foi realizada uma entrevista, com roteiro semiestruturado, contemplando os seguintes eixos temáticos: cuidados na primeira infância, dimensões da maternidade e conjugalidade. As participantes foram selecionadas a partir de contatos informais em diferentes redes de sociabilidade da pesquisadora. As entrevistas foram agendadas com antecedência, a partir da disponibilidade das participantes, tiveram duração média de uma hora, foram realizadas pela própria pesquisadora, gravadas em áudio e transcritas integralmente.

\section{Procedimentos éticos}

O projeto de pesquisa que deu origem a este estudo foi aprovado pelo Comitê de Ética da universidade onde foi desenvolvido. Todas as participantes assinaram o termo de consentimento livre e esclarecido, concordando com a utilização dos dados coletados para fins de pesquisa e publicação científica, preservada a identidade delas e de suas famílias.

\section{Análise dos dados}

Os dados foram analisados por meio do método de análise de conteúdo, tal como proposto por Bardin (2011), em sua vertente categorial. As categorias foram criadas a partir das respostas com significados semelhantes entre si, seguindo o critério semântico de categorização. Do discurso das participantes emergiram várias categorias de análise. Para atingir os objetivos propostos neste estudo, serão apresentadas e discutidas as seguintes categorias de análise: sofrimentos do puerpério; rede de apoio; e a história nãofoi bem assim... 


\section{Resultados e discussão}

Baby blues

Tornar-se mãe e dar vida a um bebê é um momento sensível, que implica uma série de transformações. As participantes definem o puerpério como um período de emoções intensas, ressaltando os sofrimentos vivenciados por elas.

Porque a gente deixa de ser quem a gente era assim, e ai é dificil porque tudo muda, o corpo muda, você olha pro espelho ai você vê um quadril mais largo, um peito maior, um tronco mais largo, você tá mais gorda do que você era, suas roupas não cabem mais, isso vem tudo junto, é... ai vem com a insegurança do seu casamento não ser mais o mesmo... Eu no começo, quando eu tive o baby blues, eu perguntava assim: Quando é que eu vou assistir televisão com o meu marido de novo... eu ficava super nervosa com isso porque eu pensava, gente... você fica com medo da sua relação não ser mais a mesma, do seu trabalho não ser mais o mesmo. (Mãe 9)

... ela depende da gente pra tudo, tudo, tudo, tudo, então vira um fardo no sentido assim o tempo todo é preenchido com essas atividades que é só pra criança, a gente se esquece por completo e a falta de uma noite de sono inteira, tudo isso estressa demais... Parece que a gente toma um caixote e não tá vendo a praia ... não consegue ainda visualizar com a cabeça pra fora do mar ... eu acho que tem muita preocupação, eu sou preocupada demais até hoje, mas é... do novo, o novo causa essa, né, essa... esse medo, eu já sou medrosa por natureza, mas assim quando envolve uma criança, né, nosso filho, eu fiquei assim paralisada ... eu chorava muito, eu chorei muito, muito, muito, muito... (Mãe 8)

De baby blues eu fiquei umas duas semanas. Fiquei de 15 a 20 dias, assim. Eu chorava por qualquer coisa, qualquer coisa. Era uma exaustão, uma exaustão muito grande, né? ... eu acho que o que eu mais senti, o que mais tive dificuldade foi a questão do sono, né? ... Eu lembro de ter sido, assim, bem punk... Eu não conseguia, eu não conseguia distinguir as sensações, as emoções, era tudo muito confuso, um tempo eu tava bem, logo depois eu já tava, sabe, triste, e ai era uma angústia muito grande. Então eu tinha uma dificuldade pra... pra verbalizar isso, não conseguia verbalizar, porque nem eu entendia o que eu tava sentindo. (Mãe 1)

... são muitas, muitas variáveis de sentimentos, são muitos sentimentos diferentes e picos de estresse e de relaxamento, de paz, de horror, de pânico, é uma esquizofrenia total... (Mãe 4)
Esse novo estado descrito pelas entrevistadas corrobora o que Stern (1997) nomeou de constelação da maternidade, originada pela chegada do bebê e formada por novas sensações, medos, anseios e fantasias. Nesse sentido, pode-se dizer que a mãe, de fato, reorganiza sua identidade, ao transpor o seu papel de filha para ocupar o papel de mãe e inaugurar uma nova geração. A mãe 9 expõe seus medos, inseguranças, e sua sensação de deixar de ser quem foi, com as mudanças no corpo, na rotina de trabalho e do casal; a mãe 8 acentua os esforços que a mãe precisa fazer em direção ao filho para atender suas demandas, redimensionando sua vida. Como foi ressaltado por Stern (1997) e por Maldonado (2013), essas transformações se mostram necessárias para que a mãe possa fazer um novo arranjo dos seus investimentos emocionais e da sua distribuição de energia, tempo e atividades. As experiências reveladas pelas entrevistadas, como a mudança de foco para o bebê, as mudanças no corpo e a dificuldade de encontrar espaço para as suas necessidades, se alinham à combinação de perdas e adaptações que a puérpera vivencia, apontada por Sarmento e Letúbal (2003) como características do baby blues.

As falas das mães demonstram que, dentre as vivências nas semanas subsequentes ao parto, destacam-se o choro, a falta de descanso e a instabilidade emocional. Esses dados estão consonantes com a literatura que afirma serem o choro repentino, a instabilidade de humor (Bass \& Bauer, 2018; Davidson, 2016; M’baïlara et al., 2005) e má qualidade de sono (Bass \& Bauer, 2018; Davidson, 2016; Maliszewska et al. 2016) os principais sintomas do baby blues. As participantes revelam mudanças repentinas de humor e grande conturbação interna: a mãe 8 diz ter se sentido "tomando um caixote na praia", a mãe 1 declara que em um momento "chorava, ai depois eu ria. Era uma coisa, assim, muito louca" e a mãe 4 alude a uma "esquizofrenia total". Com efeito, Jayasankari et al. (2018) mostram que o baby blues é referido por algumas mulheres como uma "montanha-russa emocional". Esse estado é descrito na literatura como uma reação emocional a sentimentos intensos, que conduz a uma labilidade afetiva e não a um estado de tristeza (M'baïlara et al., 2005).

Nas falas a seguir, as mães revelam sentimentos de incapacidade e preocupação, mas ressaltam que não tiveram rejeição ao filho.

... o puerpério é um momento muito difícil, ... é difícil, emocionalmente se conectar e ter esses cuidados, né? ... eu acho que não existem sentimentos conhecidos, palavras que se... tem muito medo, né, de... existe muito medo, porque é um ser muito frágil, como assim eu sou capaz só porque eu carreguei ela na barriga, porque fui eu que fiz... é... muito medo de tá fazendo coisa errada. (Mãe 4)

Quando eu converso com pessoas assim mais especializadas, dizem que não foi uma depressão pós-parto porque em nenhum momento eu levei isso 
pra ela assim, eu não tinha rejeição à ela, eu não tinha raiva dela, nada disso, mas eu tive um baby bluezão assim [risos]... bem... e tinha sempre uma sensação disso assim... tinha uma sensação de que não era natural, não era pra eu ser mãe, porque aí eu comecei a entrar numa de... Caramba, se minha placenta não alimentou ela o suficiente, depois você não tem leite o suficiente, sabe? De repente não é do meu organismo pra ser mãe [se emociona], entrava nessa nóia, e eu acho que eu sempre tive uma coisa... Ih, tô me emocionando! Eu acho que eu sempre tive uma coisa certinha e nota 10 e então me dava uma sensação de tá falhando, de tá errando, de não tá no controle, eu acho que isso foi o mais dificil da maternidade. (Mãe 5)

Eu tive um baby bluezinho assim... uns oito dias só chorava assim, mas eu não negava ela nem nada, eu tinha uma hiper preocupação na verdade, eu achava que ela não tava respirando, eu achava que ela ia morrer. (Mãe 9)

Como podemos apreender das falas, as entrevistadas não deixaram de cuidar de seus filhos, mesmo diante de sentimentos conflituosos, como os de estar falhando e de não ser natural. As narrativas enfatizam, ao contrário, uma preocupação excessiva com o bebê e estresse emocional. Esses dados vão ao encontro dos resultados apresentados por M'baïlara et al. (2005), que evidenciam a baixa autoestima materna e altos níveis de estresse em relação aos cuidados com o bebê como aspectos significativos que contribuem para a intensidade do baby blues. Em outros estudos, as mães também apresentaram sentimentos de incapacidade e insegurança para assumir os cuidados do recém-nascido dentro do contexto de depressão pós-parto (Sousa et al., 2011; Strapasson \& Nedel, 2010). Stern (1997) insere essas sensações no tema nomeado por ele de "vidacrescimento", em que a mãe se vê como responsável por manter o seu bebê vivo, o que a faz questionar se é capaz e naturalmente dotada para isso. Cabe salientar, retomando dados da pesquisa de Bass \& Bauer (2018), que as mulheres não deixam de exercer a maternagem em razão do baby blues e que o recurso para cuidar das mães pode ser o apoio emocional.

\section{Rede de apoio}

O nascimento de um bebê, devido à sua absoluta dependência no início da vida, exige cuidado e atenção em tempo integral, o que evidencia a importância de uma rede de apoio nesse momento. As mães salientam a necessidade de ajuda com o bebê e, principalmente, do apoio emocional da sua própria mãe para que elas também se sintam cuidadas.

É uma rede de apoio, que é fundamental, nunca imaginei que fosse tão fundamental... Minha mãe ficou todos os dias comigo até os oito meses do Antônio... Quando o bebê nasce, você precisa da sua mãe, você só quer sua mãe, você não quer mais ninguém, você não quer ver mais ninguém, você não quer nem ver o bebê, você só quer a sua mãe. Assim, eu senti isso. Mãe, não sei o que fazer, tô perdida... Ai minha mãe tinha falado: Não, eu vou com você. Ela tá vindo até agora de novo, vai ficar mais quatro meses aqui, porque ela me dá apoio. (Mãe 1)

... se não fosse, por exemplo, a minha mãe, minha mãe ficou um mês aqui comigo... eu chorava horrores assim, não de tristeza não, eu chorava até quando tava feliz, eu chorava o tempo inteiro, você falava bom dia comigo eu já tava chorando, então é muita emoção junta, misturada... Minha mãe ficou um mês comigo ... e e falo assim que todo mundo tem que ter a sua mãe um tempo logo depois, porque todo mundo só quer saber do bebê e ai você fica lá, largada naquele turbilhão de emoções assim, sofrendo lá sozinha e ai a única pessoa que vai lembrar de dar comida, de botar você pra tomar banho, de fazer um carinho, de te dar um colo é sua mãe, então isso foi muito importante, minha mãe ter ficado aqui foi fundamental. (Mãe 9)

A necessidade de ser apoiada pela própria mãe corrobora pesquisa realizada por Lopes, Prochnow e Piccinini (2010) a qual aponta que, embora a importância do parceiro seja significativa para as mulheres, o destaque maior é dado ao apoio das figuras femininas, especialmente da mãe. Todavia, na contramão desses resultados, outros estudos mostram que as mães mencionam o apoio do companheiro como o mais importante (Dessen \& Braz, 2000; Zanatta, Pereira, \& Alves, 2017). A fala da mãe 1 demonstra a sensação de estar perdida e precisar de amparo e orientação; a mãe 9 relata a necessidade de se sentir cuidada. Esses dados se alinham às postulações de Bowlby (1997) e Stern (1997), que apontam que a rede de apoio é de extrema importância, não somente no auxílio aos cuidados com a criança, mas, principalmente, no acolhimento à mãe, nas suas necessidades de se sentir cuidada, valorizada e instruída. Nessa direção, Theme Filha et al. (2016) sinalizam que a presença de uma rede de apoio é um fator de proteção à maternidade, tanto o apoio instrumental quanto o afetivo, encorajando a mãe para que ela se sinta autorizada em sua função materna, além de ser considerada um dos fatores de maior importância para a prevenção da depressão pós-parto (Cardoso \& Vivian, 2018; Cunha et al., 2012; Davidson, 2016; Maliszewska et al. 2016). Ademais, a rede de apoio aumenta a responsividade da mãe à criança e promove benefícios à família (Goldstein et al.,1996; Rapoport \& Piccinini, 2006). A mãe 1 acrescenta a culpa que sentia por querer ser cuidada em um momento em que deveria estar apta a cuidar.

Eu me sentia superfeliz, mas eu também me sentia precisando de cuidado, falava: Cara, eu também 
quero ser cuidada. Que nem eu tô cuidando dele, eu quero que alguém cuide de mim. E eu não conseguia dizer isso, eu ficava... Eu não conseguia dizer isso pra minha mãe... Falar "Mãe, faz isso pra mim?". Eu não conseguia, eu chorava, ficava aflita e por mais que eu tivesse essa rede de apoio, eu era muito controladora de... Não, eu que tenho que fazer as coisas do A., ele é meu filho. Eu que tenho que assumir isso, mais ninguém... Porque eu acho que sentia culpa, não posso tá me sentindo agora num momento, eu tenho uma criança pra cuidar, como eu quero ser cuidada? Eu acho, eu imagino que eu estivesse sentindo uma culpa. (Mãe 1)

Podemos observar na fala anterior a crença de que o cuidado do filho é responsabilidade da mãe e como essa crença se desdobra em angústias pelo embate entre o que a mãe 1 acredita ser o seu papel, ou seja, ser a única cuidadora do filho, e as sensações experienciadas, contraditoriamente: desejar receber ajuda e cuidado. Como vimos, esse novo contexto que se insere com a chegada do bebê pode ativar medos na mulher, não só sobre a sua capacidade de permitir e manter uma rede de apoio, mas também sobre a possibilidade de ser julgada e criticada em seu desempenho como mãe (Stern, 1997). Historicamente, a valorização do papel da mãe e a relevância dada à sua responsabilidade em relação aos cuidados do bebê, agregam sentimento de culpa em relação às exigências sociais do seu papel (Moura \& Araújo, 2004). Assim, a mãe que se considera a única responsável pelos cuidados com o filho tende a apresentar sentimentos de ansiedade e insatisfação, como ressaltado por Beltrame e Donelli (2012).

\section{A história não foi bem assim...}

Nas narrativas a seguir, notam-se certo desconforto e culpa ante o fato de não terem, imediatamente após o parto, experimentado o sentimento de amor materno.

Foi assim, foi uma relação, né, minha com o Antônio, que a gente foi construindo dia após dia, se conhecendo... e o meu amor foi crescendo aí, não tive aquele amor. Falei: Caramba! É o amor da minha vida! Não tive isso ... eu não tive aquele amor à primeira vista, e eu senti uma culpa muito grande por isso, falando: Gente, eu não amo esse bebezinho mais que tudo. Eu amo o meu marido mais que ele, eu amo a minha mãe mais do que amo ele e foi, foi um processo até eu entender isso. (Mãe 1)

... eu romantizei achando que assim, que ela ia nascer de parto normal e que ia vir pro meu colo, e que eu ia olhar pra aquela criança e falar assim: Ah! Ai vinham aquelas florzinhas no meu coração, né, aquela borboletinha no estômago, sei lá o que, e não foi nada disso, não foi nada disso, entendeu? Primeira decepção ... a gente já se sente culpada naquele momento ... então alguém podia falar: Fica tranquila, quando nascer o alivio vai ser muito maior do que simplesmente aquele sentimento de amor, entendeu? Tá tudo bem, no primeiro momento você não vai amar o seu bichinho, você só vai ter o sentimento de cuidar e tá ok porque é isso, o amor vai construindo, ai cada dia que você olha, você fala "Ai que coisa fofa, ai você vai amando, vai amando, vai amando, esse amor vai existir, fica tranquila... ninguém fala isso, aí a gente se cobra o tempo todo". (Mãe 7)

Estes relatos corroboram a tese de Badinter (1985), que analisa o amor materno como um sentimento construído e não inato e atemporal. A partir de uma ampla pesquisa, a autora encontra ao longo da história uma multiplicidade de sentidos atribuídos à maternidade e de vivências da mulher no papel de mãe, o que a faz descortinar o que nomeia de "o mito do amor materno". Para ela, o sentimento de amar o filho(a) é adquirido pela convivência e pelos cuidados dispensados, que se desenvolvem com o tempo. Nesse sentido, os modos e representações da maternidade têm relação com os mais variados contextos e períodos, e com os desdobramentos da vida de cada mulher, não podendo o amor materno ser uma universalidade, nem ser associado ao instinto feminino. Stern (1997) ressalta o tema do envolvimento emocional da mãe com o bebê, que ele chama de "relacionar-se primário", como fortemente definido pela cultura. Desse modo, quando as disposições da mãe não encontram ressonância no seu meio social, ela pode se sentir fragilizada, defeituosa, não-natural e questionar-se sobre sua capacidade de amar.

\section{Considerações finais}

A vivência do puerpério tem se mostrado conflituosa, em decorrência das já mencionadas mudanças intrapsíquicas e interpessoais que a mulher necessita atravessar nesse período. Nas falas das participantes, podemos perceber o sofrimento associado a esse momento, em que a mulher se vê diante do dilema de precisar cuidar, enquanto se sente frágil e também precisa de auxílio.

No âmbito dessas considerações, analisamos, dentro do espectro da depressão pós-parto, como o baby blues afetou as participantes, repercutindo em grande instabilidade emocional e dificuldade de manejar tal labilidade no período de maior demanda do bebê. Nesse sentido, esta pesquisa evidenciou a necessidade de maior conscientização sobre o baby blues, o que poderá contribuir para que as mulheres vivenciem essa condição sem se sentirem anormais em virtude de seus sintomas. Tal conscientização é muito importante, visto que a maior parte das entrevistadas mencionou quão despreparadas estavam para os sentimentos que as acometeram no puerpério.

Observamos, também, associada à carência de informação sobre estas vivências, como a idealização desse período contribuiu para aumentar o sofrimento na passagem pelo puerpério. Percebemos que a visão romantizada sobre o amor materno repercute em culpas, 
frustrações e sentimentos de inadequação, por não corresponderem a esse ideal.

Ademais, o nascimento do primeiro filho instaura um novo contexto familiar, com novas demandas, o que requer maior apoio. A rede familiar, especialmente a mãe da mãe, foi considerada por nossas participantes fator preponderante para o bem-estar e acolhimento materno. Além de se sentirem extremamente fragilizadas, ainda enfrentam a dificuldade de permitirem ajuda em um período em que se espera que estejam plenamente aptas a cuidar.

É importante salientar, ainda, que o puerpério também é vivenciado pelo parceiro (Degner, 2017; Sarmento \& Letúbal, 2003), o que nos leva a considerar a relevância de estudos que investiguem os estados provocados no homem por esse período e os conflitos relacionados ao tema. Nosso objetivo centrou-se nas questões do puerpério materno, todavia, sabemos da importância de incluir o papel do pai nessa discussão. Sugerimos estudos futuros que aprofundem as questões relativas às interações triádicas, pai, mãe e filho(a), no período do puerpério e as influências destas nos estados emocionais de ambos os membros do casal.

Por fim, ressaltamos, em vista da alta correlação entre depressão pregressa e DPP (Arrais \& Araujo, 2017; Hartmann, Mendoza-Sassi, \& Cesar, 2017), a importância de investigar também a existência de episódio de depressão anterior à gravidez. Além disso, consideramos a pertinência de incluir a aplicação de instrumentos, cujos resultados apontem indícios de DPP, que possam influenciar as respostas das participantes.

\title{
I'm a mother: what now? Postpartum experiences
}

\begin{abstract}
Our study is part of a broader research on maternity and early childhood care. It aims to investigate how women experience their postpartum period today. For such purpose, a qualitative research was conducted and ten middle-class women from Rio de Janeiro were interviewed. The women were professionally active, aged between 29 and 37 years, married (formally or otherwise), primiparous, heterosexual, and who had a child aged between eight months and two years old. The results were analyzed according to the content analysis method and its categorical aspect. To achieve the goals of this study, we discussed the following analysis categories: baby blues; support network; and "It was not quite like that...". The results showed that women idealizes the postpartum period, actually experiencing distress and emotional instability. We emphasize the importance of the support network for both mothers and their children.
\end{abstract}

Keywords: maternity, postpartum period, baby blues, support network.

\section{Je suis mère : et maintenant ? Expériences du post-partum}

Résumé : La présente étude s'inscrit dans le cadre d'une recherche plus large sur la maternité et les soins de la petite enfance, et vise à examiner comment les femmes vivent actuellement le post-partum. Une recherche qualitative a été menée, au cours de laquelle dix femmes âgées de 29 à 37 ans, de la classe moyenne de Rio de Janeiro ont été interviewées. Elles étaient mariées (officiellement ou non), hétérosexuelles, primipares et avaient un enfant âgé de 8 mois à 2 ans. Les résultats ont été analysés selon la méthode d'analyse du contenu catégorique. Pour atteindre les objectifs de cette étude, les catégories d'analyse suivantes ont été discutées : baby blues; réseau de soutien ; et "Cela ne s'est pas tout à fait passée comme-ça... ». Les résultats montrent que la période post-partum était idéalisée par les femmes, mais vécue avec souffrance et instabilité émotionnelle. Nous soulignons l'importance du réseau de soutien pour les mères et les enfants.

Mots-clés : maternité, période post-partum, baby blues, réseau de soutien.

\section{Soy mamá: ¿y ahora? Vivencias del puerperio}

Resumen: El presente estudio forma parte de una investigación más amplia acerca de la maternidad y los cuidados en la primera infancia y tiene como objetivo investigar la forma en la que las mujeres viven el postparto en la actualidad. Por lo anterior, se llevó a cabo una investigación cualitativa, en la que fueron entrevistadas diez mujeres de clase media de la población de Río de Janeiro, activas profesionalmente, con edades entre los 29 y los 37 años, casadas legalmente o no, heterosexuales, primíparas y con hijo/a de entre 8 meses y 2 años de edad. Se analizaron los resultados según la técnica de análisis de contenido en su vertiente categorial. Para alcanzar los objetivos de este estudio, se discutirán las siguientes categorías de análisis: baby blues; red de apoyo; y la historia no era como la contaban.... Los resultados mostraron que el puerperio es un periodo idealizado por las mujeres, pero es vivido con sufrimiento e inestabilidad emocional. Se corroboró la importancia de la red de apoyo tanto para la madre como para el bebé.

Palabras clave: maternidad, puerperio, baby blues, red de apoyo. 


\section{Referências}

Arrais, A. R., \& Araujo, T. C. C. F. (2017). Depressão pós-parto: Uma revisão sobre fatores de risco e de proteção. Psicologia, Saúde e Doenças, 18(3), 828-845.

Azevedo, K. R., \& Arrais, A. D. R. (2006). O mito da mãe exclusiva e seu impacto na depressão pós-parto. Psicologia: reflexão e crítica, 19(2), 269-276.

Badinter, E. (1985). Um amor conquistado: O mito do amor materno. Rio de Janeiro, RJ: Nova Fronteira.

Bardin, L. (2011). Análise de Conteúdo. Lisboa: Edições 70.

Bass, P., \& Bauer, N. (2018). Parental postpartum depression: More than "baby blues". Contemporary Pediatrics, 35(9).

Beltrame, G. R.; Donelli, T. M. S. (2012). Maternidade e carreira: Desafios frente à conciliação de papéis. Aletheia, (38-39), 206-217.

Bowlby, J. (1997). Formação e rompimento dos laços afetivos. 3a ed. São Paulo, SP: Martins Fontes.

Cardoso, A. C. A., \& Vivian, A. G. (2018). Maternidade e suas vicissitudes: A importância do apoio social no desenvolvimento da díade mãe-bebê. Diaphora, 6(1), 43-51.

Costa, A. O. (2018). Depressão, autoestima e satisfação conjugal no ciclo gravídico puerperal: Implicações para a maternidade (Dissertação de Mestrado em Psicologia da Saúde). Universidade Metodista de São Paulo, São Bernardo do Campo.

Cunha, A. B., Ricken, J. X., Lima, P., Gil, S., \& Cyrino, L. A. R. (2012). A importância do acompanhamento psicológico durante a gestação em relação aos aspectos que podem prevenir a depressão pós-parto. Saúde $e$ Pesquisa, 5(3), 579-586.

Davidson, M. R. (2016). Postpartum Depression. In Encyclopedia of Family Studies (pp. 1-4). Hoboken: Wiley.

Degner, D. (2017). Differentiating between "baby blues," severe depression, and psychosis. BMJ, 359.

Dessen, M. A., \& Braz, M. P. (2000). Rede social de apoio durante transições familiares decorrentes do nascimento de filhos. Psicologia: Teoria e Pesquisa, 16(3), 221-231.

Goldstein, L. H., Diener, M. L., \& Mangelsdorf, S. C. (1996). Maternal characteristics and social support across the transition to motherhood: Associations with maternal behavior. Journal of Family Psychology, 10(1), 60-71.

Hartmann, J. M., Mendoza-Sassi, R. A., \& Cesar, J. A. (2017). Depressão entre puérperas: Prevalência e fatores associados. Cadernos de Saúde Pública, 33(9), 1-10.

Jayasankari, P. P. M. R. S., Kirthika, A. K. I. T., Priya, E. M. N. M. S., \& Varghese, R. S. R. S. E. (2018). A study to explore the factors contributing to the development of postpartum blues among postnatal mothers at Pondicherry Institute of Medical Sciences, Puducherry. International Journal of Advances in Nursing Management, 6(4), 309-312.

Kibler, N., \& Wells, P. (2019). Beyond the baby blues: Cross-cultural perspective on perinatal mental health. In
19 National Cross-Cultural Counseling and Education Conference for Research, Action, and Change. Savannah, GA.

Kołomańska-Bogucka, D., \& Mazur-Bialy, A. I. (2019). Physical activity and the occurrence of postnatal depression: a systematic review. Medicina, 55(9), 560.

Lima, N. C., Ravelli, A. P. X., Messias, L. S. F., \& Skupien, S. V. (2016). Depressão pós-parto baseada na escala de Edimburgo. Revista Conexão UEPG, 12(2), 268-277.

Lobato, G., Moraes, C. L. \& Reichenheim, M. E. (2011). Magnitude da depressão pós-parto no Brasil: Uma revisão sistemática. Revista Brasileira de Saúde Materno Infantil, 11(4), 369-379.

Lopes, R. D. C. S., Prochnow, L. P., \& Piccinini, C. A. (2010). A relação da mãe com suas figuras de apoio femininas e os sentimentos em relação à maternidade. Psicologia em estudo, 15(2), 295-304.

M'baïlara, K., Swendsen, J., Glatigny-Dallay, E., Dallay, D., Roux, D., Sutter, A. L., ... \& Henry, C. (2005). Baby blues: Characterization and influence of psycho-social factors. L'Encephale, 31(3), 331-336.

Maldonado, M. T. (2013). Psicologia da gravidez. Rio de Janeiro, RJ: Jaguatirica Digital.

Maliszewska, K., Świątkowska-Freund, M., Bidzan, M., \& Preis, K. (2016). Relationship, social support, and personality as psychosocial determinants of the risk for postpartum blues. Ginekologia Polska, 87(6), 442-447.

Manente, M. V., \& Rodrigues, O. M. P. R. (2016). Maternidade e trabalho: Associação entre depressão pós-parto, apoio social e satisfação conjugal. Pensando Familias, 20(1), 99-111.

Melo, E. F. D., Jr. (2011). Prevalência de depressão perinatal e fatores associados (Tese de Doutorado). Faculdade de Ciências Médicas, Universidade Estadual de Campinas, Campinas.

Moura, S. M. S. R., \& Araújo, M. F. (2004). A maternidade na história e a história dos cuidados maternos. Psicologia: Ciência e Profissão, 24(1), 44-55.

Rapoport, A., \& Piccinini, C. A. (2006). Apoio social e experiência da maternidade. Revista Brasileira de Crescimento e Desenvolvimento Humano, 16(1), 85-96.

Sarmento, R.; Letúbal, M. S. V. (2003). Abordagem psicológica em obstetrícia: Aspectos emocionais da gravidez, parto e puerpério. Revista de Ciências Médicas, 12(3), 361-268.

Silva, G. A. (2013). Prevalência de depressão pós-parto em países desenvolvidos e em desenvolvimento: Contribuições metodológicas de uma metanálise (Tese de Doutorado). Instituto de Psicologia, Universidade de São Paulo.

Sousa, D. D., Prado, L. C., \& Piccinini, C. A. (2011). Representações acerca da maternidade no contexto da 
depressão pós-parto. Psicologia: Reflexão e Crítica, 24(2), 335-343.

Stern, D. N. (1997). A constelação da maternidade. Porto Alegre, RS: Artes Médicas. (Trabalho original publicado em 1995)

Strapasson, M. R.; Nedel, M. N. B. (2010). Puerpério imediato: Desvendando o significado da maternidade. Revista Gaúcha de Enfermermagem, 31(3), 521-528.

Theme Filha, M. M., Ayers, S., Gama, S. G. N., \& Leal, M. C. (2016). Factors associated with postpartum depressive symptomatology in Brazil: The Birth in Brazil National
Research Study, 2011/2012. Journal of Affective Disorders, 194, 159-167.

Zanatta, E., Pereira, C. R. R., \& Alves, A. P. (2017). A experiência da maternidade pela primeira vez: As mudanças vivenciadas no tornar-se mãe. Pesquisas $e$ Práticas Psicossociais, 12(3), 1-16.

Recebido: $21 / 12 / 2020$

Revisado: $19 / 03 / 2021$

Aprovado: 10/04/2021 